\title{
La salvajería del amor
}

\author{
Por Emmy Ruvalcaba O. \\ Universidad de Sonora \\ Alumna del $V$ semestre de la Licenciatura en Música \\ ruvalcabaemmy@gmail.com
}

\section{Introducción}

El objetivo de este trabajo es comprender el paradigma que condiciona al amor en la actualidad. Nos basamos en tres textos. El primero un clásico: Simposio (Banquete) o de la erótica de Platón, donde tomaremos las posturas de Pausanias y Aristófanes. El segundo una publicación de Edgar Morin de 1997 titulada El complejo del amor donde se pone en relación la noción de paradigma con la definición de amor y, finalmente, el texto Estética y Modernidad de Valeriano Bozal, del cual rescataremos la noción de estética y lo aplicaremos en el ámbito del amor.

Los textos señalados los leemos a través de tres conceptos claves: sujeto contemporáneo, sensibilidad contemporánea y paradigma, los cuales nos permiten analizar las lecturas señaladas desde la época que nos sujeta.

\section{Sujetos de la época}

La época es el hoy, el presente al que nos enfrentamos día a día, puedes o no darte cuenta de ella, pero al estar consciente de tu alrededor y al mirar las luces y además poder percibir la oscuridad que hay en ella es cuando se empieza a ser sujeto contemporáneo (Agamben, 2011). El autor que comentamos presenta dos definiciones de sujeto contemporáneo. En la primera señala:

Pertenece en verdad a su tiempo, es en verdad contemporáneo aquel que no coincide a la perfección con este ni se adecua a sus pretensiones, y entonces, en este sentido, es inactual; pero, justamente por esto, a partir de ese alejamiento y ese anacronismo, es más capaz que los otros de percibir y aferrar su tiempo (p. 18).

Esto, definiéndolo con base en lo señalado por Nietzsche, pone al sujeto contemporáneo como alguien que se siente muy adelantado para la época que vive, en cierta forma rechaza la época, pero es consiente que está en ella y lucha por vivir en ella.

Mientras que, en la segunda afirma: "Contemporáneo es aquel que mantiene la mirada fija en su tiempo, para percibir, no sus luces, sino su oscuridad" (Agamben, 2011, p. 21). Refiriéndose a que el sujeto contemporáneo descubre la tiniebla de la época y no se deja cegar por la luz instalando una relación entre los tiempos.

Es el contemporáneo el que quebró las vértebras de su tiempo (o en todo caso percibió su falla o su punto de ruptura), él hace de esa fractura el lugar de una cita y de un encuentro entre los tiempos y las generaciones (p. 28).

Aquí es donde la noción de sensibilidad contemporánea comienza a aparecer, que simplificando las ideas de Sánchez Vázquez (1992), se puede decir que la sensibilidad contemporánea es la forma en que nos relacionamos con los objetos y más específicamente con objetos del pasado y cómo influyen estos en nosotros y en nuestra actualidad.

Adentrándonos en la noción de paradigma, se puede decir que el paradigma nos hace ciegos y para darnos cuenta de su existencia, este tiene que estar en crisis 
(Kuhn, 2004), incluso, podríamos decir que es una construcción imaginaria:

Lo apócrifo de nuestro mundo se prueba por la existencia de la lógica, por la necesidad de poner el pensamiento de acuerdo consigo mismo, de forzarlo, a que solo vea lo supuesto o puesto por él con exclusión de todo lo demás (Machado, 1936).

Teniendo en cuenta las nociones mencionadas anteriormente, podemos abrir el tema del paradigma que rodea al amor, basándonos en el texto del Banquete de Platón y el de Complejo de amor de Edgar Morin.

\section{Paradigma del amor}

Amor es el nombre que le damos al conjunto de sentimientos, el cual, aún después de tanto tiempo no podemos dar una definición exacta de dicha palabra. En el complejo del amor, Morin nos dice algo importante donde la definición no es lo que realmente importa:

El amor a la vez procede de la palabra y precede a la palabra. Es un problema interesante, porque hay culturas en las que no se habla del amor. En esas culturas en donde el amor no ha emergido como palabra, ¿existe el amor? ¿O más bien su existencia pertenece a lo no dicho? (Morin, 1997, p. 11).

Así desde siempre, este concepto ha variado según el punto de vista de las personas, las vivencias, donde el concepto de amor se vuelve más personal y de un carácter más espiritual. Un ejemplo de lo dicho se encuentra en el texto clásico de Platón ya que tomando el punto de vista de Pausanias en el Banquete, el amor no se explica sin Venus (refiriéndose a la belleza) y hay dos tipos de Venus, la antigua hija del cielo y que no tiene madre y la Venus más joven, hija de Jupiter y de Dione, donde la primera es una belleza sensual, brutal, que se dirige a los sentidos y la segunda se dirige a la inteligencia. Esto también es muy común hasta nuestros días pues podemos clasificar a la atracción tanto física como intelectual. Aunque este texto data del año 380 A.C. en él se puede inferir que en cuanto al amor, seguimos preguntándonos y creyendo lo mismo. Otro ejemplo de ello es lo dicho por Aristófanes en el Banquete (Platón, 2005/1962) acerca del tercer tipo de hombres. Los primeros dos son los hombres y las mujeres, en el tercero recurre a un mito donde dos seres andróginos forman una especie superior a las dos anteriores pues estos seres eran dobles y del mismo sexo unidos por el ombligo quienes sentían amor el uno por el otro, tomaron tanta fuerza (sienten que se pueden enfrentar a los dioses), que Júpiter decidió dividirlos haciendo que cuando las dos partes se encontraran no fuera posible su reproducción, desde entonces la reproducción se hizo de la unión de hombre con mujer y la sociedad hizo que se separaran los seres del mismo sexo.

Lo dicho por Aristófanes se puede relacionar actualmente con el concepto de media naranja, esto es el no sentirse completos y saber que hay alguien en algún lado que está destinado a ser su otra mitad, que llena el vacío. Otro concepto que podemos relacionar es el de la homosexualidad, ya desde ese entonces se puede hablar de ello como algo positivo, pues habla que la unión de estos dos seres del mismo sexo es tan fuerte como para que Júpiter temiera de su poder, por lo que la palabra amor es planteada y restringida por el orden social, el cual dicta lo que es correcto y lo que no, dentro de él. Actualmente la homosexualidad se sigue tocando como tema tabú pues la sociedad tiene un sistema moral que dicta al ser humano que es lo que está bien y que es lo que está mal, lo mismo sucede con la belleza física y la belleza intelectual, como lo señalamos anteriormente.

Adentrándonos en el texto Estética y Modernidad de Valeriano Bozal, podemos ver que el gusto no es universal: 
El subjetivismo propio de algunos autores del siglo XVII anida en la reflexión de Hume, en especial cuando afirma que la belleza no es una cualidad de las cosas mismas; existe sólo en la mente que la contempla y cada mente percibe una belleza diferente (Bozal, 2003, p. 430).

Pero al igual que el sistema moral que rige en el ser humano, también se habla de un sistema estético que es más bien colectivo, pues el autor que comentamos, habla de él como una forma que tiene el ser humano con el fin de socializar y de educarse.

El gusto como rasgo no meramente individual, sino colectivo y sirve para comprender la educación estética como una forma de socialización (me atrevo a decir, como parte de la educación general, que permite la «delicadeza del gusto») (Bozal, 2003, p. 431).

Y podemos ver estos cánones estéticos en nuestra vida diaria, centrándonos principalmente en la belleza física, donde el cuerpo ideal es el de "Barbie", cuando en la televisión solo encuentras actores y actrices delgados y bronceados y en los videos musicales y los mismos músicos ya no es tan importante que tan bueno o que tanto talento se tiene, sino que tan perfecto es el cuerpo que luce.

Pero además Bozal, en base al texto Sobre la norma del gusto de Humme, hace la distinción entre un juicio estético de lo que puede ser bello y un sentimiento pues el sentimiento no puede ser juzgado, solo se puede hablar de un sentimiento real o no real pues no se puede hablar de él como si fuera correcto o no, solo es un sentimiento y lo importante en él es si este existe o si no, a diferencia del juicio estético el cual si puede ser verdadero o falso pues como dije anteriormente, este se rige por un sistema estético.

Mientras que el juicio puede ser verdadero o falso, en tanto que posee referencia a algo fuera de sí, no sucede lo mismo con el sentimiento, que no afecta a nada exterior $\mathrm{y}$ "es siempre real en tanto que un hombre sea consciente de él”. El sentimiento siempre es correcto, o, mejor dicho, no tiene mucho sentido hablar de él como de correcto o de incorrecto, verdadero o falso, porque no es ése su ámbito adecuado. Se produce o no se produce: resulta de la adecuación entre el sujeto y el objeto (Bozal, 2003).

Aplicando esto al tema del amor, este puede ser concebido de igual manera en que podemos relacionarnos con un objeto estético, tanto física como intelectualmente pues un juicio estético, si lo aplicamos así, hacia una persona, puede ser o no correcto en base a lo que la sociedad y los medios nos han dicho que es bello $\mathrm{y}$ feo pero un sentimiento no se puede cuestionar, solamente puede o no estar ahí, por ello es tan difícil definir lo que es el amor, pues nos hemos planteado esa pregunta desde la edad antigua, con los filósofos griegos hasta nuestra actualidad que seguimos buscando una respuesta.

La cuestión de la salvajería del deseo y de la fascinación del amor se plantea en relación con el orden social. La humanidad creó instituciones, instituyó la exogamia, las reglas del parentesco, prescribió el matrimonio, prohibió el adulterio (Morin, 1997).

Pero a pesar de lo impuesto por la moral y la estética, una vez que el amor llega, el orden social es lo que menos importa.

\section{Conclusión}

Desde Platón, el ser humano ha hablado de la palabra amor, desde entonces se ha preguntado y ha puesto en debate su significado, sin éxito. A pesar de los cambios y avances, no existe una definición exacta de esta palabra ya que es muy compleja pues varía según la persona que responda este cuestionamiento, esto se debe a la relación directa que tiene con los sentimientos, dependiendo de las vivencias y 
experiencias de cada persona, por lo que ninguna definición es correcta o incorrecta.

A pesar de lo anterior mencionado, la temporalidad no afecta a la palabra, un ejemplo de ello es la mención de Pausanias sobre los dos tipos de amor, el físico y el intelectual (mencionados como belleza), que en la actualidad no son ajenos a nosotros y podemos entender perfectamente lo que quiere dar a entender el diálogo a pesar de ser del año 380 a.
C., otro ejemplo es la mención de la homosexualidad que se hace en ese mismo texto y donde menciona la separación de las parejas del mismo sexo. Por ello, el paradigma que rodea al amor llega cuando nos damos cuenta de la crisis que vivimos cuando este se nos presenta, ya que debemos cumplir con ciertas normas que existen en el orden social, y cuando las rompemos el paradigma se hace visible, lo que nos hace preguntarnos: Entonces, ¿qué es el amor?

\section{Bibliografía}

Agamben, G. (2011). ¿Qué es lo contemporaneo? En G. Agamben, Desnudez (págs. 17 - 29). Buenos Aires: Adriana Hidalgo.

Bozal, V. (2003). Estética y Modernidad. Madrid: Editorial Trotta. D., L. D. (2015). Acerca de la noción de paradigma. En A. Machado, S,T (págs. S, P). Kuhn, T. (2004). La estructura de las revoluciones científicas (A. Contin, Trans.). México: Fondo de Cultura Económica.

Morin, E. (1997). El complejo de amor. En E. Morin, El complejo de amor.

Platón. (2005/1962). Simposio (Banquete) o de la erótica. México: Editorial Porrúa. Sánchez Vázquez, A. (1992). Invitación a la estética (1era ed ed.). Grijalbo: México. Machado, A. (1936). José María Valverde, Juan de Mairena: Sentencias, donaires, apuntes y recuerdos de un profesor apócrifo. Madrid: Editorial Castalia. 